\title{
ANALISIS KEBUTUHAN STAKEHOLDER DALAM MENGEMBANGKAN MODEL TATA KELOLA TI MENGENAI TRANSPARANSI PENGADAAN SISTEM INFORMASI PADA PEMERINTAH KOTA MAKASSAR BERDASARKAN COBIT 5
}

\author{
Irfan AP
}

\begin{abstract}
Optimized of management Information
Technology related aspects of both internal and

external software such as networking, it can not be done sporadically personalized level management or policy makers. IT management issues has been experiencing a transition from technology issues into problems of management and governance. It was triggered by the increasing dependence and the need for the field of Information Technology. In today's modern era of information technology should be managed as well as manage other assets as a strategy for continuity of service of an agency / company.

However along with the requirement also escalate issues of how to ensure that information technology is applied in accordance with the needs and functions. As well important how to control the transparency of the procurement of Information Technology is not abused and that the application is not appropriate. For it was imperative for government agencies to have a reference model suitable of IT Governance as required and expected. This study successfully identified the presence of 3 (three) CobIT 5 process to be used as the IT Governance models that can be applied, they are; EDM02, EDM03, and EDM05.
\end{abstract}

Keywords—CobIT 5, IT Governance, Transparency, Government.

\section{PENDAHULUan}

$\mathrm{S}$

seiring dengan kebutuhan akan penerapan Teknologi Informasi juga menimbulkan problem bagaimana memastikan bahwa Teknologi Informasi yang diterapkan tersebut sesuai dengan kebutuhan dan fungsinya. Juga tidak kalah penting bagaimana mengontrol transparansi pengadaan Teknologi Informasi tersebut sehingga tidak disalahgunakan serta penerapan yang tidak tepat guna. Untuk itu sangat mendesak bagi instansi pemerintah memiliki acuan model Tata Kelola akan transparansi pengadaan sistem informasi sebagai koridor penerapan dan pengelolaanTeknologi Informasi sesuai dengan yang dibutuhkan dan diharapkan.

Penelitian ini bertujuan melakukan analisa serta bagaimana menyusun Model Tata Kelola Teknologi Informasi di Instansi Pemerintah di Kota makassar, yang berkaitan dengan transparansi pengadaan Sistem Informasi. Berdasarkan kerangka kerja CobIT 5 Sehingga diperoleh gambaran model Tata Kelola TI yang dapat diusulkan menjadi acuan penyusunan Tata Kelola Teknologi Informasi di Instansi pemerintah.

\section{Metode Penelitian}

Penelitian ini berdasarkan pada kerangka kerja CobIT 5, dan dijalan sesuai alur proses seperti pada Gambar 1. 


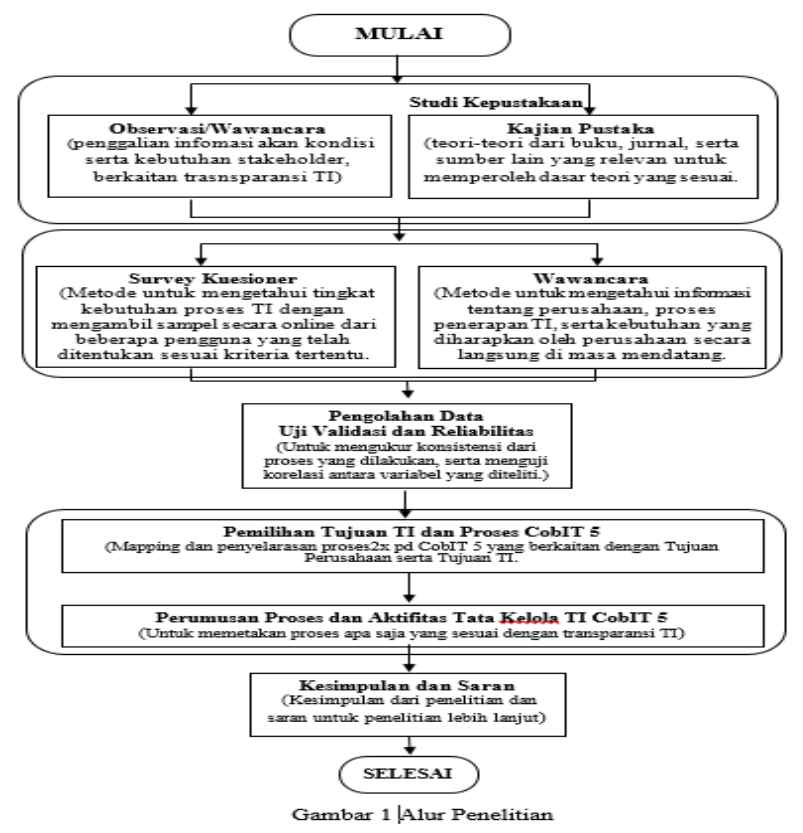

\section{HASIL DAN PEMBAHASAN}

Proses pembahasan dimulai dengan pengumpulan data yang berasal dari penyebaran kuesioner dengan jumlah reponden yang lengkap sebanyak 44 orang yang terdiri atas masyarakat, akademisi, industry, legislasi, dan internal Pemkot Makassar. Hasil rekapitulasi data seperti tabel 1.

Tabel 1. Rekapitulasi jawaban kuesioner

\begin{tabular}{|c|c|c|c|c|c|}
\hline Mengetahui & Penting & Anggaran & Stakeholder & Transparansi & Jumlah \\
\hline 12 & 0 & 0 & 1 & 10 & 23 \\
\hline 9 & 10 & 35 & 5 & 2 & 61 \\
\hline 9 & 2 & 0 & 9 & 0 & 20 \\
\hline 0 & 0 & 9 & 0 & 0 & 9 \\
\hline 14 & 18 & 0 & 27 & 32 & 91 \\
\hline 0 & 14 & 0 & 0 & 0 & 14 \\
\hline 44 & 44 & 44 & 42 & 44 & 218 \\
\hline
\end{tabular}

\subsection{Uji Data}

Sebelum data yang telah diperoleh dapat dilanjutkan untuk dianalisa terlebih dahulu data tersebut diuji validitas dan reliabilitasnya.

\subsubsection{Validitas}

Suatu kuesioner dikatakan valid jika pertanyaan dalam kuesioner benar-benar mampu mengukur indikator variabel yang kita inginkan.

Nilai yang diperoleh pada Pearson correlation harus diuji signifikasinya. Bila nilai pada kolom tersebut signifikan pada alpha 5\% sesuai tabel $\mathbf{r}$ hitung, maka dapat dinyatakan bahwa data yang terkandung dalam variabel tersebut valid (Kaiser dan Rice, 1976), (Aswar.1999).

Dari hasil uji validasi berdasarkan teknik Bivariate Pearson, semua hasil skor total melebihi nilai signifikan 0,05 tabel $\mathbf{r}$ hitung yaitu diatas 0,248 untuk total skor Perason Correlation uji 2 sisi (2tailed). Hal ini menunjukkan bahwa pertanyaan masing-masing variabel dinyatakan valid. 


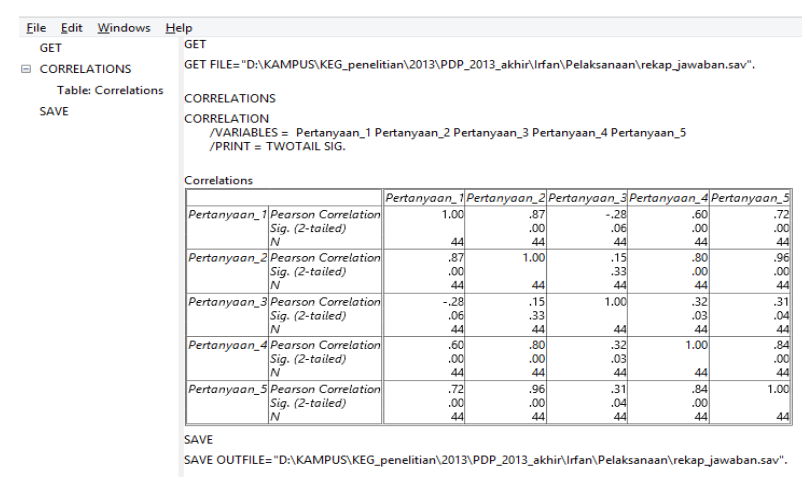

\subsubsection{Reliabilitas}

Hasil observasi di uji dengan memanfaatkan software GNU/Linux PSPP dengan uji statistik Cronbach Alpha. Suatu kuesioner dinyatakan reliabel jika menghasilkan perhitungan cronbach alpha > 0.60 (osterhof,2001).

Tabel 3. Hasil Uji Reliabilitas

Case Processing Summary
\begin{tabular}{|c||r|r|}
\hline & $N$ & \multicolumn{1}{c|}{$\%$} \\
\hline Cases Valid & 44 & 97.78 \\
Excluded & 1 & 2.22 \\
Total & 45 & 100.00 \\
\hline
\end{tabular}

Reliability Statistics

\begin{tabular}{|r|r|}
\hline Cronbach's Alpha & Nof Items \\
\hline .87 & 5 \\
\hline
\end{tabular}

Output yang dihasilkan oleh Software PSPP GNU/Linux diatas menunjukkan bahwa nilai cronbach alpha adalah 0,87. Capaian nilai cronbach alpha yang lebih besar dari 0,6 mengindikasikan bahwa data kuesioner termasuk handal/ reliabel.

\subsection{Pemilihan Proses Referensi Tata Kelola TI}

Pada kerangka kerja CobIT 5 memiliki perbedaan dengan CobIT 4 mengenai proses evaluasi ini, pada CobIT 4 proses ini dikenal dengan proses evaluasi level tertinggi (high level control objective). Namun pada CobIT 5 proses ini disebut proses referensi, dimana adanya pembagian yang jelas antara proses manajemen dan proses tata kelola.

Pemilihan proses referensi tata kelola TI ini mengacu pada Renstra Pemkot Makassar yang salah satu isu strategisnya adalah "Good Governance". Isu strategis ini selanjutnya di jabarkan pada visi an misi Pemkot Makassar, pada kajian kali ini "enterprise goal" dirumuskan dari misi-nya yaitu pada bagian ke-lima dimana dinyatakan " Mengembangkan system pemerintahan yang baik, bersih dan berwibawa melalui peningkatan profesionalme aparatur".

\subsubsection{Kebutuhan Stakeholder}

Tata Kelola TI dimulai dari kebutuhan stakeholder, seperti yang tergambarkan pada Gambar 2. 


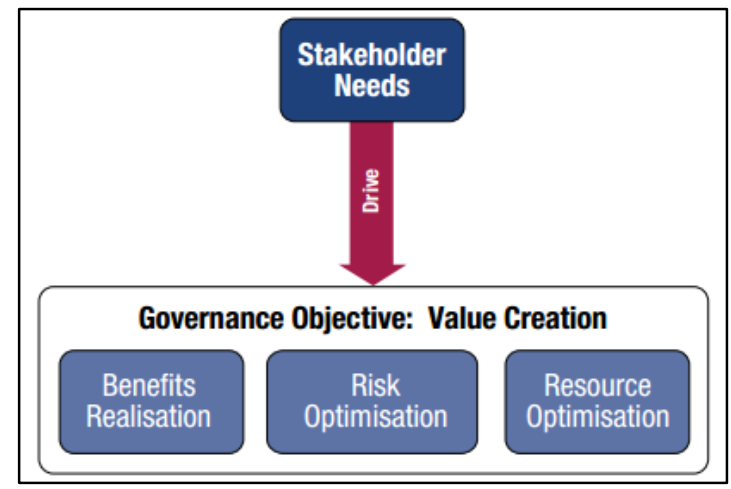

Gambar 2. Kebutuhan Stakeholder

Untuk itu, pada proses ini kegiatan pengumpulan data serta analisa tujuan perusahaan dalam hal ini Pemkot Makassar menghasilkan informasi yang sesuai berdasarkan hasil kuesioner seperti pada gambar 3.

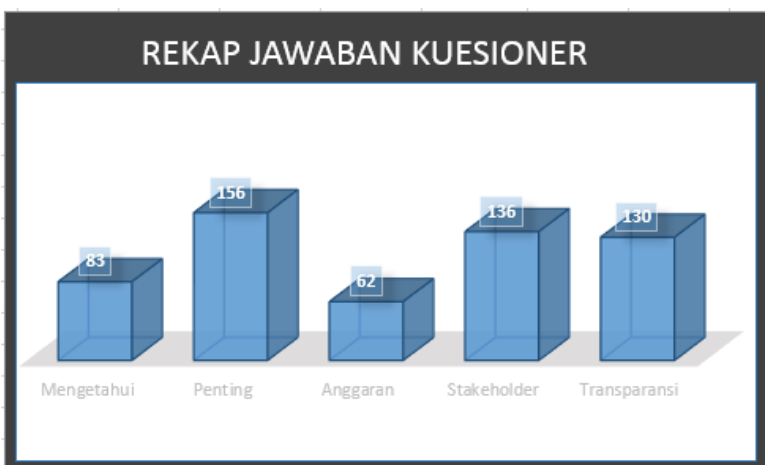

Gambar 3. Hasil analisa kebutuhan stakeholder

Dari gambar tersebut dapat diuraikan bahwa kebutuhan stakeholder akan model Tata Kelola TI diPemkot Makassar berkaitan dengan pengadaan system informasi, diperoleh urutan kebutuhan sebagai berikut:

1. Pentingnya penerapan Tata Kelola TI

2. Stakeholder memegang peranan vital dalam optimalisasi Tata Kelola TI

3. Transparansi stakeholder.

4. Pemahaman Tata Keelola TI.

5. Pengelolan anggaran.

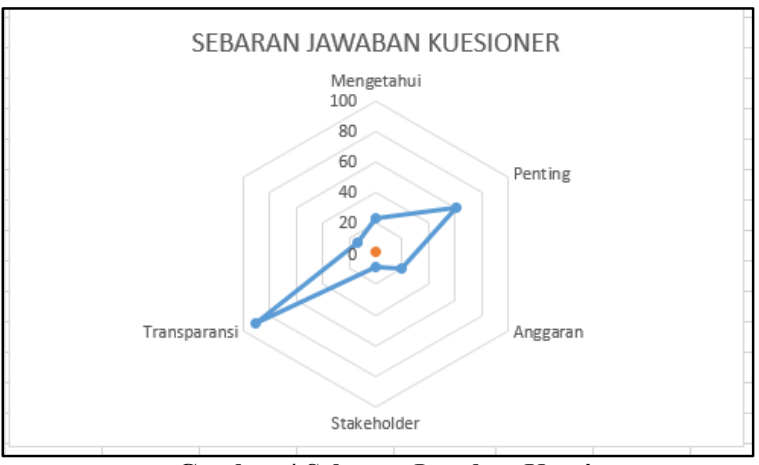

Gambar 4 Sebaran Jawaban Kuesioner

\subsubsection{Pemetaan Tujuan Pemerintah Kota Makassar dan Tujuan yang Berkaitan TI}


Langkah selanjutnya kita melakukan pemetaan dari tujuan perusahaan dan TI sehingga kita menemukan IT-Process yang sesuai dengan lingkup Tata Kelola TI, yang dalam peneiltian ini dijumpai bahwa proses Tata Kelola yang relevan dengan tujuan Pemkot Makassar adalah Proses CobIT 5 pada EDM02, EDM03, dan EDM05.

Seperti yang tampak pada gambar 5, mengenai pemetaan tersebut ketiga Proses CobIT 5 adalah merupakan proses utama dalam kegiatan Tata kelola TI.

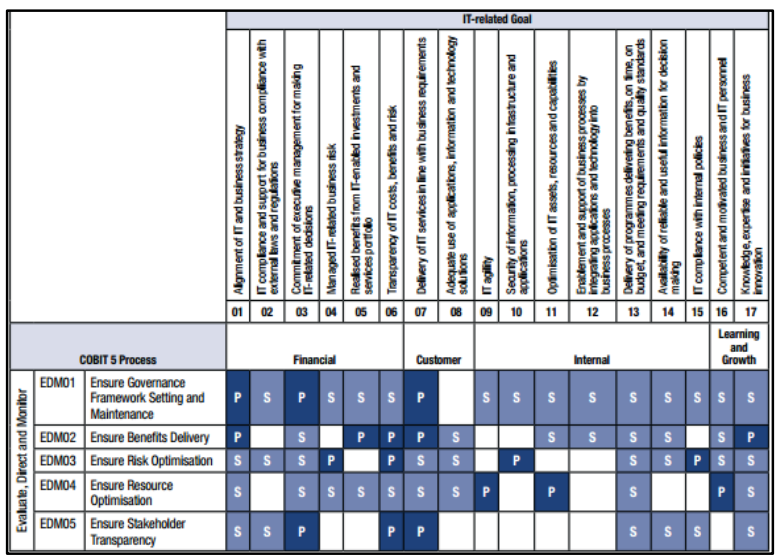

Gambar 5. Proses CobIT 5 EDM

Namun pada penelitian ini proses CobIT 5 yang difokuskan adalah EDM05, hal berdasarkan ruang lingkup dan data yang diperoleh dari proses tanya jawab, maupun kuesioner yang menunjukkan bahwa sebagian besar dominan pada kegiatan Transparency Stakeholder.

\section{KESIMPULAN}

Hasil dari penelitian menunjukkan bahwa kebutuhan akan penerapan Tata Kelola TI dalam upaya menciptakan Tata Kelola Pemerintahan yang baik adalah sangat vital, sebagaimana indikator berikut:

1. Hasil analisa menunjukkan terdapat 2 (dua) komponen utama Tata Kelola TI menjadi konsen utama yang diharapkan dapat diterapkan yaitu Pengelolaan Stakeholder dengan 136 harapan dari responden, dan adanya tranparansi dengan 130 data responden.

2. Berhasil mengidentifikasi adanya 3 (tiga) proses CobIT 5 untuk dijadikan model Tata Kelola TI yang dapat diterapkan, meliputi; EDM02, EDM03, dan EDM05.

Untuk menghasilkan model Tata Kelola TI yang komprehensif, sebaiknya ketiga proses CobIT 5 yaitu EDM02, EDM03, dan EDM05 agar diimplementasikan secara bersama-sama karena masingmasing proses saling melengkapi dan menunjang.

\section{SARAN}

Untuk menghasilkan model Tata Kelola TI yang komprehensif, sebaiknya ketiga proses CobIT 5 yaitu EDM02, EDM03, dan EDM05 agar diimplementasikan secara bersama-sama karena masingmasing proses saling melengkapi dan menunjang.

\section{DAFTAR PUSTAKA}

[1] CobIT 5 (2012), Enabling Proceses, Rolling Meadows, IL-USA.

[2] IT Governance Institute/ ITGI (2007), IT Governance Implementation Guide, Using CobIT and Val IT, Illinois

[3] IT Governance Institute/ ITGI (2008), Understanding How Business Goals Drive IT Goals, Executive Briefing, Illinois 
[4] Moeller, Robert R, (2008), Sarbanes-Oxley, Internal Control, Efective auditing with AS5, Cobit and Itil, Jon Wiley \& Sons, Inc., Hoboken, New Jersey.

[5] Van Grembergen, Wim, (2008), Implementing Information Technology Governance: Model, practice and cases, IGI Publishing, Chocolate Avenue, Hershey PA.

[6] Sarno, Riyanarto, (2009), Audit Sistem dan Teknologi Informasi, ITS Press, Surabaya.

[7] Moeller, Robert R, (2010), IT Audit, Control and security, Jon Wiley \& Sons, Inc., Hoboken, New Jersey.

[8] AP Irfan, Lianto B Joko, 2012, tata kelola ti untuk proses pengelolaan layanan pihak ketiga pada penyedia web hosting makassartech dotcom menggunakan framework cobit 4.1, Proseeding Semnas Manajemen Teknologi XV, MMT-ITS, Surabaya.

[9] AP, Irfan, 2013, penyelarasan tujuan bisnis dan tujuan teknologi informasi untuk pemilihan proses evaluasi dalam internal kontrol ti berdasarkan control objective for information and related technology (cobit), Proseeding Semnas Semantik 2013, Udinus, Semarang. 